\title{
Effect of PEEP decremental on respiratory mechanics, gas exchange, pulmonary regional ventilation and hemodynamics in patients with SARS-Cov-2 associated Acute Respiratory Distress Syndrome
}

\author{
Vincent Bonny ${ }^{1 *}$, Vincent Janiak ${ }^{2,3}$, Savino Spadaro ${ }^{4,5}$, Andrea Pinna ${ }^{2}$, Alexandre Demoule ${ }^{1,6}$ and Martin Dres ${ }^{1,6}$
}

To the editor:

Previous reports of severe acute respiratory syndrome coronavirus 2 (SARS-Cov-2)-related acute respiratory distress syndrome (ARDS) have been highlighting a profound hypoxemia and it is not yet well defined how to set positive end-expiratory pressure (PEEP) in this context [1]. In this report, we describe the effects of two levels of PEEP on lung mechanics using a multimodal approach.

Patients with confirmed laboratory SARS-Cov-2 infection and meeting criteria for ARDS according to the Berlin definition [2] were eligible within the $48 \mathrm{~h}$ after intubation. Written informed consent was waived due to the observational nature of the study. The local ethic approved the study ( $\mathrm{N}^{\circ}$ CER-2020-16).

Patients were paralyzed and received lung protective ventilation on volume-controlled ventilation. Effects of PEEP decremental were evaluated at two levels of PEEP, arbitrarily $16 \mathrm{~cm} \mathrm{H}_{2} \mathrm{O}$ and $8 \mathrm{~cm} \mathrm{H}_{2} \mathrm{O}$. These levels were decided based on previous reports [3, 4]. Measurements were performed after $20 \mathrm{~min}$ after changing the level of PEEP. Lung mechanics were assessed using an esophageal catheter (NutriVentTM, Italy) [5]. Hemodynamics, indexed extravascular lung water (EVLWi), pulmonary vascular permeability index (PVPI), and cardiac function index (CFI) were monitored by transpulmonary

\footnotetext{
* Correspondence: v.bonny@hotmail.fr

'Sorbonne Université, INSERM, UMRS1158 Neurophysiologie respiratoire expérimentale et clinique, Paris, France

Full list of author information is available at the end of the article
}

thermodilution (TPTD) device $\left(\mathrm{PiCCO}_{2}\right.$, Pulsion Medical Systems, Germany). Pulmonary regional ventilation was monitored by the use of an EIT belt placed around the patient's chest (PulmoVista500; Dräger Medical GmbH Lübeck, Germany) [6].

Ten patients were enrolled and the effects of two levels of PEEP decremental are displayed in Table 1. The PEEP decremental significantly increased both cardiac index and cardiac function index but did not significantly influence other TPTD-related variables. PEEP decremental was not associated with significant changes in gas exchange but was associated with a significant decrease in plateau pressure and driving pressure and with a significant decrease in end-inspiratory and in endexpiratory transpulmonary pressures. Lung compliance was significantly higher at low PEEP. Regarding pulmonary regional ventilation, PEEP decremental resulted in a loss of lung impedance associated with a decrease in dorsal fraction. By contrast, decreasing PEEP did not affect global inhomogeneity index. Best PEEP according to the lowest relative alveolar collapse and overdistension was 12 [11-13] $\mathrm{cm} \mathrm{H}_{2} \mathrm{O}$.

These findings suggest that mechanically ventilated SARS-Cov-2 patients have a relatively preserved lung compliance and that the use of high PEEP was associated with a decrease in lung compliance while providing no beneficial effect on gas exchange. Dorsal part of the lung partially collapsed at low PEEP compared to high PEEP. It may suggest that our patients needed a level of PEEP greater than $8 \mathrm{~cm} \mathrm{H}_{2} \mathrm{O}$. This was actually 
Table 1 Changes in hemodynamics, gas exchange, respiratory mechanics, and pulmonary regional ventilation between high and low PEEP in supine $(n=10)$

\begin{tabular}{|c|c|c|c|}
\hline & High PEEP & Low PEEP & $P$ \\
\hline \multicolumn{4}{|l|}{ Clinical variables } \\
\hline Heart rate, beats. $\mathrm{min}^{-1}$ & 72 [64-95] & 76 [59-97] & 0.977 \\
\hline Systolic arterial blood pressure, mmHg & 125 [108-138] & 129 [118-140] & 0.555 \\
\hline Diastolic arterial blood pressure, $\mathrm{mmHg}$ & 63 [49-69] & $58[48-65]$ & 0.158 \\
\hline Mean arterial blood pressure, $\mathrm{mmHg}$ & 77 [72-89] & 77 [73-86] & $>0.999$ \\
\hline \multicolumn{4}{|l|}{ Transpulmonary thermodilution indices } \\
\hline Cardiac index, L. $\min ^{-1} \cdot \mathrm{m}^{-2}$ & $2.5[2.0-3.0]$ & $2.6[2.2-3.3]$ & 0.027 \\
\hline Global end-diastolic volume indexed, mL.m ${ }^{-2}$ & $661[551-870]$ & 668 [559-813] & 0.432 \\
\hline Extravascular lung water, mL.kg ${ }^{-1}$ & 15 [13-18] & 14 [13-17] & 0.551 \\
\hline Pulmonary vascular permeability index & $3.3[2.7-3.9]$ & $3.3[2.7-3.6]$ & 0.607 \\
\hline Cardiac function index, $\min ^{-1}$ & $4.4[2.4-5.3]$ & $4.5[2.8-5.8]$ & 0.008 \\
\hline \multicolumn{4}{|l|}{ Gas exchanges } \\
\hline $\mathrm{pH}$ & $7.35[7.29-7.37]$ & $7.35[7.30-7.41]$ & 0.305 \\
\hline $\mathrm{PaCO}_{2}, \mathrm{mmHg}$ & $45[39-51]$ & $44[40-47]$ & 0.191 \\
\hline $\mathrm{PaO}_{2} / \mathrm{FiO}_{2}$ ratio, mmHg & 116 [99-196] & 106 [86-129] & 0.127 \\
\hline $\mathrm{SaO}_{2}, \%$ & 97 [95-98] & 96 [92-97] & 0.172 \\
\hline$V_{D} / V_{T}$ & $0.34[0.29-0.39]$ & $0.35[0.30-0.39]$ & 0.348 \\
\hline A-a gradient, $\mathrm{mmHg}$ & 374 [304-533] & $384[275-543]$ & 0.139 \\
\hline \multicolumn{4}{|l|}{ Respiratory mechanics } \\
\hline Respiratory rate, breaths. $\mathrm{min}^{-1}$ & $27[23-30]$ & $27[23-30]$ & - \\
\hline Tidal volume, $\mathrm{mL} . \mathrm{kg}^{-1} \mathrm{IBW}$ & $6.0[6.0-6.3]$ & $6.0[6.0-6.3]$ & - \\
\hline Positive end-expiratory pressure, $\mathrm{cmH}_{2} \mathrm{O}$ & $16[16-16]$ & $8[8-8]$ & 0.016 \\
\hline Peak pressure, $\mathrm{CmH}_{2} \mathrm{O}$ & $44[42-47]$ & 35 [33-36] & 0.002 \\
\hline Plateau pressure, $\mathrm{cmH}_{2} \mathrm{O}$ & $28[27-31]$ & 20 [18-21] & 0.002 \\
\hline Driving pressure, $\mathrm{CmH}_{2} \mathrm{O}$ & 14 [11-16] & $12[10-13]$ & 0.004 \\
\hline End-expiratory transpulmonary pressure, $\mathrm{cmH}_{2} \mathrm{O}$ & $6[4-8]$ & $2[-1-4]$ & 0.002 \\
\hline End-inspiratory transpulmonary pressure, $\mathrm{cmH}_{2} \mathrm{O}$ & $14[13-17]$ & $9[6-10]$ & 0.002 \\
\hline Respiratory system compliance, ml. $\mathrm{cmH}_{2} \mathrm{O}^{-1}$ & 29 [27-36] & $34[30-42]$ & 0.012 \\
\hline Respiratory system resistance, $\mathrm{cmH}_{2} \mathrm{O} \cdot \mathrm{L}^{-1} \cdot \mathrm{sec}^{-1}$ & $0.24[0.20-0.25]$ & $0.23[0.22-0.26]$ & $>0.999$ \\
\hline Lung compliance, ml.cmH ${ }_{2} \mathrm{O}^{-1}$ & $47[40-56]$ & $64[46-82]$ & 0.008 \\
\hline$R / I$ ratio & \multicolumn{2}{|c|}{$0.33[0.21-0.54]$} & - \\
\hline End-expiratory lung volume, $\mathrm{mL}$ & $2546[2151-3019]$ & 1725 [1450-2023] & 0.002 \\
\hline \multicolumn{4}{|l|}{ Electrical impedance tomography derived indices } \\
\hline Dorsal fraction, \% & $46[43-54]$ & 35 [32-39] & 0.002 \\
\hline Global inhomogeneity index, \% & 58 [52-60] & $60[55-66]$ & 0.059 \\
\hline End-expiratory lung impedance & $251[179-404]$ & 139 [83-243] & 0.008 \\
\hline Changes in end-expiratory lung impedance, \% & \multicolumn{2}{|c|}{$-118[-150$ to -32$]$} & 0.004 \\
\hline
\end{tabular}

Data are presented as median [interquartile range] or number (percentage). Wilcoxon matched pairs signed-rank test was used to evaluate differences between the median values of paired data. $\mathrm{PaCO} 2$ partial pressure of arterial carbon dioxide, $\mathrm{PaO} 2$ partial pressure of oxygen, $\mathrm{FiO} 2$ fraction of inspired oxygen, $\mathrm{SaO}_{2}$ oxygen saturation, $V_{D} V_{T}$ estimated dead space fraction, A-a gradient alveolar-arterial gradient, $R / l$ recruitment to inflation ratio. $P$ values refer to the comparison between high and low PEEP for each patient 
confirmed by the EIT PEEP titration maneuver. Otherwise, it is interesting to point out that the "best PEEP" according to EIT $\left(12 \mathrm{~cm} \mathrm{H}_{2} \mathrm{O}\right)$ was close to PEEP set by the clinicians (14 [11-16] $\mathrm{cm} \mathrm{H}_{2} \mathrm{O}$ ). Whether larger tidal volumes would have mitigated the dorsal lungs collapse remains speculative and will have to be tested in further studies. This suggests that the increase in lung volume at high PEEP was more likely the result of overdistension of non-dependent part of the lungs than a recruitment of dependent ones (Fig. 1). This interpretation is reinforced by the GI which remained unchanged, indicating stability in the inhomogeneous distribution of ventilation throughout the lungs.

This study is the first to describe a multimodal approach of SARS-Cov-2-related ARDS but the findings are limited by the small sample size and the early timing of the evaluation.

In conclusion, this series of SARS-Cov-2-related ARDS describe an individualized multimodal approach of lung mechanics, gas exchange, pulmonary regional ventilation, and hemodynamics at the early phase of the disease and suggest that low PEEP should be used as part of the ventilation strategy, rather than high PEEP.

\section{Acknowledgements}

We thank Umar Saleem for his contribution to this work.

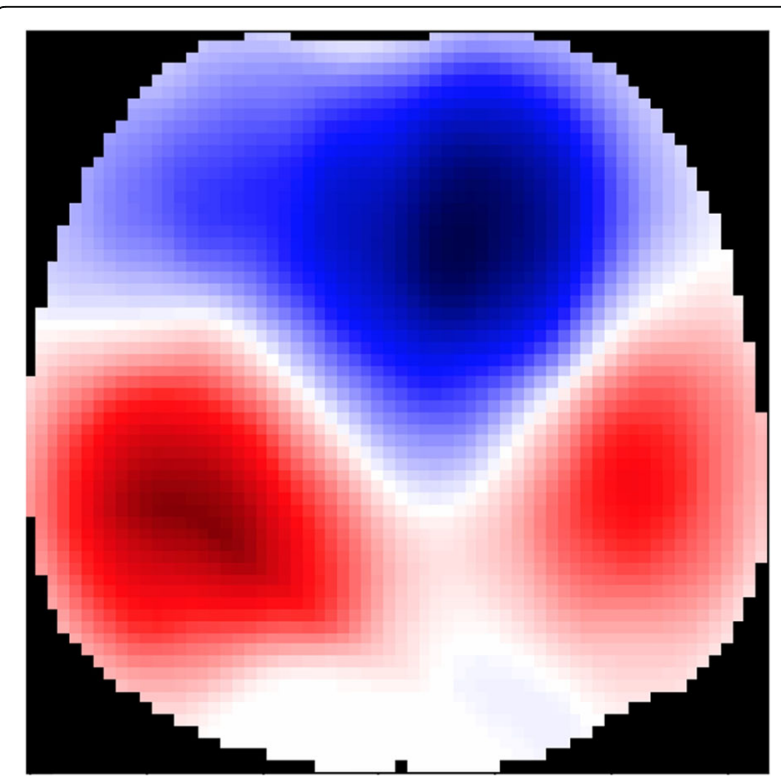

Fig. 1 Regional ventilation measured by electrical impedance tomography at low PEEP. Change in topographic distribution of tidal ventilation after a decremental PEEP. Blue areas show a gain in ventilation, and red areas show a loss of ventilation. Right side of the patient is to the left of the image. Back side of the patient is to the bottom of the image

\section{Authors' contributions}

Conceptualization: MD, AD, and VB. Acquisition, analysis, or interpretation of the data: MD, VJ, and VB. Statistical analysis: MD and VB. Investigation: MD, $A D$, and $V B$. Drafting the manuscripts and editing: $V B, V J, S S, A P, A D$, and MD. Funding acquisition: Not applicable. Supervision: MD. All the authors involved read and approved the final manuscript.

\section{Funding}

Vincent Bonny received a grant from the Fondation du Souffle and Fonds de Recherche en Santé Respiratoire (Formation par la Recherche 2019).

\section{Availability of data and materials}

Drs. Vincent Bonny, Martin Dres, and Professor Alexandre Demoule had full access to all the data in the study. After publication, the data will be made available to others on reasonable requests after approval from the corresponding author (VB, v.bonny@hotmail.fr).

\section{Ethics approval and consent to participate}

Ethics approval was received by the Research Ethics Committee of Sorbonne University approved the study (№2020_CER-2020-16). Written informed consent was waived due to the observational nature of the study.

\section{Consent for publication}

The informed consents of patients were waived by the Research Ethics Committee of Sorbonne University approved the study for the rapid emergence of this epidemic.

\section{Competing interests}

AD reports personal fees from Medtronic; grants, personal fees and nonfinancial support from Philips; personal fees from Baxter; personal fees from Hamilton; personal fees and non-financial support from Fisher \& Paykel; grants from the French Ministry of Health; personal fees from Getinge; grants, personal fees, and non-financial support from Respinor; grants, personal fees, and non-financial support from Lungpacer; and personal fees from Lowenstein, outside the submitted work.

The other authors declare to have no competing interests.

\section{Author details}

${ }^{1}$ Sorbonne Université, INSERM, UMRS1158 Neurophysiologie respiratoire expérimentale et clinique, Paris, France. ${ }^{2}$ Sorbonne Université, UPMC Univ Paris 06, INSERM, Sorbonne Paris Cité, Université Paris 13, LIMICS, UMR_S 1142, Paris, France. ${ }^{3}$ Bioserenity, 20 rue Berbier-du-Mets, 75013 Paris, France. ${ }^{4}$ Department of Morphology, Surgery and Experimental Medicine, University of Ferrara, Ferrara, Italy. ${ }^{5}$ Anaesthesia and Intensive Care Unit, Sant'Anna Hospital, Aldo Moro, Ferrara, Italy. ${ }^{6}$ AP-HP. Sorbonne Université, Hôpital Pitié-Salpêtrière, Service de Pneumologie, Médecine intensive - Réanimation (Département "R3S"), F-75013 Paris, France.

Received: 5 August 2020 Accepted: 24 September 2020

Published online: 06 October 2020

\section{References}

1. Gattinoni L, Chiumello D, Caironi P, Busana M, Romitti F, Brazzi L, et al. COVID-19 pneumonia: different respiratory treatments for different phenotypes? Intensive Care Med. 2020; s00134-020-06033-2. https://doi. org/10.1007/s00134-020-06033-2.

2. Acute Respiratory Distress Syndrome. The Berlin definition. JAMA. 2012;307 https://doi.org/10.1001/jama.2012.5669.

3. Mauri T, Spinelli E, Scotti E, Colussi G, Basile MC, Crotti S, et al. Potential for lung recruitment and ventilation-perfusion mismatch in patients with the acute respiratory distress syndrome from coronavirus disease 2019*. Crit Care Med. 2020;48:1129-34 https://doi.org/10.1097/CCM.0000000000004386.

4. Chen L, Del Sorbo L, Grieco DL, Junhasavasdikul D, Rittayamai N, Soliman I, et al. Potential for lung recruitment estimated by the recruitment-toinflation ratio in acute respiratory distress syndrome. A clinical trial. Am J Respir Crit Care Med. 2020;201:178-87 https://doi.org/10.1164/rccm.2019020334OC.

5. The PLeUral pressure working Group (PLUG - Acute Respiratory Failure section of the European Society of Intensive Care Medicine), Mauri T, Yoshida T, Bellani G, Goligher EC, Carteaux G, et al. Esophageal and transpulmonary pressure in the clinical setting: meaning, usefulness and 
perspectives. Intensive Care Med. 2016;42:1360-73 https://doi.org/10.1007/ s00134-016-4400-X.

6. Frerichs I, Amato MBP, van Kaam AH, Tingay DG, Zhao Z, Grychtol B, et al. Chest electrical impedance tomography examination, data analysis, terminology, clinical use and recommendations: consensus statement of the TRanslational EIT developmeNt stuDy group. Thorax. 2017;72:83-93 https://doi.org/10.1136/thoraxjnl-2016-208357.

\section{Publisher's Note}

Springer Nature remains neutral with regard to jurisdictional claims in published maps and institutional affiliations.

Ready to submit your research? Choose BMC and benefit from:

- fast, convenient online submission

- thorough peer review by experienced researchers in your field

- rapid publication on acceptance

- support for research data, including large and complex data types

- gold Open Access which fosters wider collaboration and increased citations

- maximum visibility for your research: over $100 \mathrm{M}$ website views per year

At BMC, research is always in progress.

Learn more biomedcentral.com/submissions 